\title{
Prader-Willi and Angelman Syndromes: Diagnosis With a Bisulfite-Treated Methylation-Specific PCR Method
}

\author{
Kenjiro Kosaki, ${ }^{1}$ Matthew J . McGinniss, ${ }^{2}$ Alexey N. Veraksa, ${ }^{3}$ William J . McGinnis, ${ }^{3}$ and \\ Kenneth Lyons J ones ${ }^{1 *}$ \\ ${ }^{1}$ Division of Dysmorphology, Department of Pediatrics, University of California, San Diego, La J olla, California \\ 2Molecular Genetics Laboratory, Children's Hospital-San Diego, San Diego, California \\ ${ }^{3}$ Department of Biology, University of California, San Diego, La J olla, California
}

The putative promoter region of the SNRPN gene contains a CpG island which is heavily methylated in the maternally derived allele and unmethylated in the paternally derived allele. In patients with Prader-Willi syndrome (PWS) only the methylated allele is present, while in those with Angelman syndrome (AS) only the unmethylated allele is present. The purpose of this paper is to report a polymerase chain reaction (PCR)based assay to evaluate methylation status of the C pG island of the SNRPN gene and to show that this assay allows rapid diagnosis of PWS and AS. Methylated cytosines in the CpG dinucleotide are resistant to chemical modification by sodium bisulfite. In contrast, bisulfite treatment converts all unmethylated cytosines to uracil. Based on this differential effect, the bisulfitemodified DNA sequence of a methylated allele was successfully distinguished from that of an unmethylated al lele using 2 sets of allele-specific primer pairs: a methylated allele-specific primer pair (MET) and an unmethylated allele-specific primer pair (UNMET). Bisulfite-modified DNA from 10 patients with PWS amplified only with the MET pair while modified DNA from 5 patients with AS amplified only with the UNMET pair. Modified DNA from 50 normal unrelated individuals amplified with both primer pairs. In that methylation-specific PCR (MSPCR) can detect all presently testable causes of PWS and AS in a rapid and

Contract grant sponsor: Children's Hospital-San Diego Research Center.

*Correspondence to: Kenneth Lyons J ones, M.D., Division of Dysmorphology, Department of Pediatrics, University of California, San Diego, 200 West Arbor Drive \#8446, San Diego, CA 92103-8446.

Received 10 March 1997; Accepted 9 J une 1997 cost-effective fashion, serious consideration should be given to the use of this test in the initial evaluation of all patients in which PWS or AS is being considered. Am. J . Med. Genet. 73:308-313, 1997. ๑ 1997 Wiley-Liss, Inc.

\section{KEY WORDS: Prader-Willi syndrome; An- gelman syndrome; SNRPN; methylation; C pG island}

\section{INTRODUCTION}

Regardless of the cause (deletion [Nicholls et al., 1989a; Robinson et al., 1991; Mascari et al., 1992], uniparental disomy [Nicholls et al., 1989b; Robinson et al., 1991; Mascari et al., 1992], and rare imprinting mutations [Nicholls, 1993; Reis et al., 1994; Sutcliffe et al., 1994; Buiting et al., 1995]), patients with Prader-Willi syndrome (PWS) inherit only a maternally derived methylated allele in the promoter region of the SNRPN (small nuclear ribonucleoprotein polypeptide N) gene [Glenn et al., 1996]. More than $80 \%$ of patients with Angelman syndrome (AS) have a deletion [Knoll et al., 1989; Magenis et al., 1990; Williams et al., 1990; Zackowski et al., 1993], uni parental disomy [Malcolm et al., 1991; Nicholls et al., 1992], or an imprinting mutation. For all of these only a paternally derived unmethylated allele is present at the locus, regardless of the cause. Normal individuals have 1 unmethylated and 1 methylated allele [Glenn et al., 1996]. At present, digestion by methylation-sensitive restriction enzymes followed by Southern blotting with the the PW71B probe [Glenn et al., 1993; Gillessen-Kaesbach et al., 1995] or the SNRPN probe [Glenn et al., 1996; Kubota et al., 1996] is employed for molecular diagnosis of PWS and AS.

In this study the methylation status of a CPG island in the putative promoter region of the SNRPN gene was evaluated by the methylation-specific polymerase chain reaction (MSPCR) [Herman et al., 1996]. MSPCR entails chemical modification of cytosine to uracil by sodium bisulfite, in which methylated cytosines in the CPG dinucleotides are resistant to the modification 
[Shapiro et al., 1973; Wang et al., 1980; Clark et al., 1994], and subsequent PCR amplification with primer pairs specific for either the methylated or the unmethylated allel es. Using primer pairs specific for the methylated allele (MET) and the unmethylated allele (UNMET), the methylation status of the SNRPN gene was studied in samples from patients with PWS and AS, and from normal unrelated individuals, and also from amniocytes, sperm, and various somatic tissues from a 17 -week fetus. DNA from nonhuman primates was analyzed in order to test whether the priming sites for the oligonucleotide primers are evolutionarily conserved.

\section{METHODS Primer Design}

From the published genomic sequence of the $5^{\prime}$ flanking region of exon -1 of the SNRPN gene (formerly known as exon alpha) [Sutcliffe et al., 1994; Glenn et al., 1996] (GenBank accession number: L32702), DNA sequences of the methylated and the unmethylated alleles after bisulfite modification were deduced (Fig. 1): The sequence for modified unmethylated strand was determined by converting all cytosines to thymines. The sequence for the modified methylated strand was determined by converting all cytosines to thymines with the exception of those in the CpG dinucleotide. The sense strand and antisense strand of the genomic DNA are not complementary to each other after bisulfite modification. Two sets of primer pairs were designed so that they would amplify the modified sense strand and its complementary strand: one set specific for modified MET, and a second for modified UNMET. A third primer pair was developed for unmodified DNA (WT). Expected product sizes from WT, MET, and UNMET primer pairs were 145, 131, and 164 base pairs, respectively (Table I).

\section{Subjects and Materials}

This study was approved by the institutional review board of Children's Hospital-San Diego. PWS and Angelman syndrome (AS) patients in this study were evaluated at the University of California, San Diego and at Children's Hospital-San Diego. Clinical diagnosis was confirmed by a Southern blot analysis using probe PW71B at locus D15S63 [Dittrich et al., 1992]. In addition, cell line GM09133 (PWS deletion) was obtained from the NIGMS Human Genetic Mutant Cell Repository. DNA samples from 50 unrelated anonymous normal individuals were used as controls. These samples were coded by laboratory number and no patient names or identifiers were retained for use in this study. Coded DNA samples from normal individuals, PWS, and AS patients were analyzed in blind tests. The appropriate informed consent was obtained on clinical diagnostic tests of all patients with PWS and AS evaluated in this study. DNA samples of 50 normal unrelated individuals were derived from anonymous samples of persons presenting for clinical diagnostic or parentage testing in the molecular genetics laboratory at Children's Hospital-San Diego.

Human tissues including brain, heart, lung, kidney, adrenal gland, and skin were collected at autopsy from a 17-week structurally normal fetus. Sperm DNA was separated by a differential cell Iysis procedure [Guisti et al., 1986]. Genomic DNA obtained from a western lowland gorilla (Gorilla g.g.), a "common" chimp (Pan trogl odytes), and a "pygmy" chimp (Pan paniscus) were kindly provided by Dr. O.A. Ryder.

\section{Sodium Bisulfite Modification}

Genomic DNA was treated with sodium metabisulfite as described by Herman et al. [1996], with minor changes suggested by Clark et al. [1994], to ensure complete modification. In brief, genomic DNA $(1 \mu \mathrm{g})$ in

\begin{tabular}{|c|c|c|c|c|c|c|c|c|}
\hline & -110 & -100 & -90 & -80 & -70 & -60 & -10 & \\
\hline Unmodified & 5 '. cccetgcact & gcggcaaaca & agcacgcetg & cgaggecgca & gaggcaggct & ggcgcgcatg & ... gagtctggeg & CAGAGTGGA \\
\hline lethylated & $5 \cdot \ldots$ ttttgtatt & gcggtaaata & agtacgtttg & cgcggtcgta & gaggtaggtt & ggcgegtatg & $\ldots$ gagtttggcg & TAGAGTGGA \\
\hline mine & 5 '. tttttgtatt & gtggtaaata & agtatgtttg & tgtggttgta & gaggtaggtt & ggtgtgtatg & ... gagtttggtg & TAGAGTGGA \\
\hline
\end{tabular}

\footnotetext{
Unmodified $+10+20 \quad+30 \quad+40 \quad+50 \quad+60 \quad+70 \quad+80$

Methylated

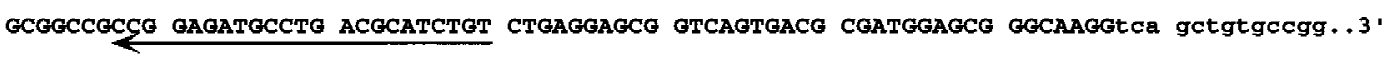

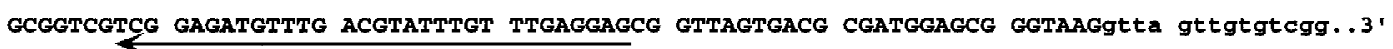

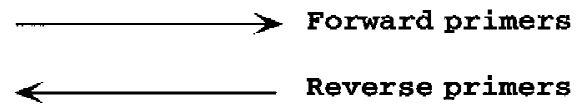

Fig. 1. Target sequences of the primer pairs for MSPCR at the putative promoter region of the SNRPN gene. Target sequences of the WT primer pair, the MET primer pair, and the UNMET primer pair are designated by arrows. Upper case letters denote the first exon (exon -1). Numbers indicate relative position from the putative transcriptional start. 
TABLE I. Primer Pairs for MSPCR of SNRPN

\begin{tabular}{|c|c|c|c|c|}
\hline & Foward primer & Reverse primer & $\begin{array}{l}\text { Annealing } \\
\text { temperature }\end{array}$ & $\begin{array}{l}\text { Product } \\
\text { size }\end{array}$ \\
\hline $\mathrm{WT}^{\mathrm{a}}$ & 5' TGCACTGCGGCAAACAAGCACGC 3' & 5' ACAGATGCGTCAGGCATCTCCGG 3' & $63^{\circ} \mathrm{C}$ & $145 \mathrm{bp}$ \\
\hline $\mathrm{MET}^{\mathrm{b}}$ & 5' CGGTCGTAGAGGTAGGTTGGCGC 3' & 5' CTCCTCAAACAAATACGTCAAACATCTCCGA 3' & $63^{\circ} \mathrm{C}$ & $131 \mathrm{bp}$ \\
\hline UNMET $^{\mathrm{C}}$ & 5' GTGTGGTTGTAGAGGTAGGTTGGTGT 3' & 5' СААСТААССТТАСССАСТССАТСАСА 3' & $63^{\circ} \mathrm{C}$ & 164 bp \\
\hline
\end{tabular}

aWT, primer pair specific for unmmodified DNA.

bMET, primer pair specific for the methylated allele.

¿UNMET, primer pair specific for the unmethylated allele.

a $50 \mu \mathrm{l}$ volume was denatured by $\mathrm{NaOH}$ (final concentration $0.3 \mathrm{M}$ ) for $15 \mathrm{~min}$ at $37^{\circ} \mathrm{C}$. For DNA samples less than $500 \mathrm{ng}, 1 \mu \mathrm{g}$ of salmon sperm DNA (Sigma) was added as carrier DNA prior to modification. Both $10 \mathrm{mM}$ of hydroquinone (Sigma) and $2 \mathrm{M}$ sodium metabisulfite (Sigma) at pH 5.0 (pH adjusted with 10M $\mathrm{NaOH}$ ) were freshly prepared. Thirty $\mu$ l of hydroquinone and $520 \mu \mathrm{l}$ of metabisulfite solution were added to the denatured samples which were then incubated under mineral oil at $55^{\circ} \mathrm{C}$ for $16-20$ hours. Free bisulfite was removed by a desalting column (Wizard DNA Clean-up system; Promega) and purified DNA was eluted into $50 \mu \mathrm{l}$ of water. Modification was completed by $\mathrm{NaOH}$ (final concentration $0.3 \mathrm{M}$ ) treatment for 15 min at $37^{\circ} \mathrm{C}$. Modified DNA was neutralized by $3 \mathrm{M}$ ammoni um acetate, preci pitated by ethanol, and resuspended in $20 \mu$ l of water.

\section{Polymerase Chain Reaction}

The PCR amplification of the bisulfite modified DNA was performed in $50 \mu$ l reaction mixtures containing 2 $\mu \mathrm{l}$ of bisulfite-treated genomic DNA, $1 \mu \mathrm{M}$ dNTPs, 1.5 $\mathrm{mM} \mathrm{MgCl}, 50 \mathrm{mM} \mathrm{KCl}, 10 \mathrm{mM}$ Tris- $\mathrm{HCl}(\mathrm{pH} 8.3)$, and Taq DNA Polymerase (2.5 units; Boehringer Mannheim). During initial denaturation for $5 \mathrm{~min}$ at $94^{\circ} \mathrm{C}$, 40 pmoles of reverse primer were added. Thereafter, one cycle of $94^{\circ} \mathrm{C}$ for $40 \mathrm{sec}, 63^{\circ} \mathrm{C}$ for $1 \mathrm{~min}$, and $72^{\circ} \mathrm{C}$ for 1 min was repeated 5 times. During the next denaturation step, 40 pmoles of forward primer were added to the reaction mixture. The cycle of $94^{\circ} \mathrm{C}$ for $40 \mathrm{sec}, 63^{\circ} \mathrm{C}$ for $1 \mathrm{~min}$, and $72^{\circ} \mathrm{C}$ for $1 \mathrm{~min}$ was then repeated for additional 30 cycles with a final elongation step of 3 min. We adopted this thermal cycling protocol to avoid excessive primer-dimer formation when the forward primer is added at the beginning of the reaction. This observation can be explained by the fact that the forward primer was designed to anneal to the complementary strand of the modified sense strand. This complementary strand does not exist until it is synthesized by the Taq polymerase using the modified sense strand and the reverse primer as substrates. When the forward primer is added after 5 cycles during which period target molecules for the forward primer are synthesized, no significant amount of primer-dimers will result. For the WT primer pair, PCR was simply accomplished by 30 cycles of $94^{\circ} \mathrm{C}$ for $40 \mathrm{sec}, 63^{\circ} \mathrm{C}$ for 1 $\mathrm{min}$, and $72^{\circ} \mathrm{C}$ for $1 \mathrm{~min}$. PCR products $(10 \mu \mathrm{l})$ were separated on a $4 \%$ NuSieve GTG agarose gel (FMC BioProducts) in $1 \times T B E$ buffer, stained with ethidium bromide and directly visualized under UV illumination.

\section{Genomic Sequencing}

In order to validate the fact that WT, MET, and UNMET primer pairs amplified the expected templates of unmodified, modified methylated, and modified unmethylated DNA, a subset of PCR products was directly sequenced with Sequenase version 2 (United States Biochemical) under conditions specified by the manufacturer with forward or reverse primers.

\section{In Vitro Methylation Studies}

Prior to modification by sodium bisulfite, a subset of DNA samples was pretreated with the CpG methylase M.Sss I which methylates all cytosine residues to 5methyl cytosine within the double-stranded recognition sequence $5^{\prime}$..CpG.. 3' [Nur et al., 1985]. DNA was treated with M.Sss I (New England Biolabs) for 1 hour in a reaction buffer containing $50 \mathrm{mM} \mathrm{NaCl}, 10 \mathrm{mM}$ Tris- $\mathrm{HCl}, 10 \mathrm{mM} \mathrm{MgCl}$, and $1 \mathrm{mM}$ dithiothreitol supplemented with $160 \mu \mathrm{M}$ S-adenosyl methionine at $37^{\circ} \mathrm{C}$. After methylase treatment, DNA was subjected to bisulfite modification as described above.

\section{RESULTS}

The results of the MSPCR analysis on patients with PWS and AS as well as normal individuals are set forth in Table II. Further data are provided below and in the Fig. 2-4. Unmodified DNA from whole blood of 50 unrelated normal individuals amplified with the WT primer pair but not with the MET or UNMET primer pairs (Fig. 2). Bisulfite-modified DNA from those normal individuals amplified with both the MET and UNMET primer pair but not with the WT primer pair. Sequencing of the PCR products demonstrated the following: The sequence of the WT primer product precisely matched the published sequence of the putative promoter region of the SNRPN gene; in the UNMET

TABLE II. Result of the MSPCR on Patients with Prader-Willi and Angelman Syndromes, and Normal Individuals

\begin{tabular}{|c|c|c|c|}
\hline & MET only ${ }^{a}$ & $\begin{array}{l}\text { UNMET } \\
\text { only }^{\mathrm{b}}\end{array}$ & $\begin{array}{l}\text { MET and } \\
\text { UNMET }^{\mathrm{C}}\end{array}$ \\
\hline Prader-Willi syndrome & $10 / 10^{d}$ & $0 / 0$ & $0 / 0$ \\
\hline Angelman syndrome & $0 / 0$ & $5 / 5$ & $0 / 0$ \\
\hline Normal & $0 / 0$ & $0 / 0$ & $50 / 50$ \\
\hline
\end{tabular}

aMET: Only the methylated allele present.

bUNMET: Only the unmethylated allele present.

CMET and UNMET: Both the methylated and the unmethylated alleles present.

dNumerator: The number of correctly identified individuals based on the appearance of the corresponding PCR product; denominator: a total number of individuals with the respective syndrome. 


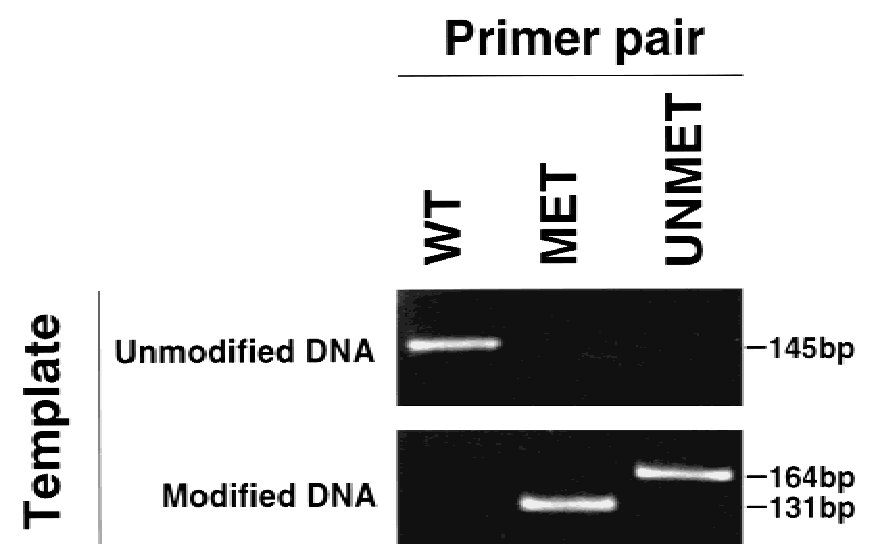

Fig. 2. Methylation analysis of the putative promoter region of the SNRPN gene in a normal individual using MSPCR. Note that unmodified DNA amplified with the unmodified WT primer pair, but not with the MET or the UNMET primer pairs; while modified DNA amplified both with the MET and the UNMET primer pairs, but not with the WT primer pair.

primer products from a normal individual, all the cytosines were converted to thymines; and in the MET primer product from a normal individual, all cytosines were converted to thymines with the exception of those in the $\mathrm{CpG}$ dinucleotide.

Modified DNA from 10 patients with PWS amplified only with the MET primer pair while modified DNA from 5 AS patients amplified only with the UNMET primer pair (Fig. 3). In the absence of the UNMET primer product, amplification with the MET primer served as control, ensuring that modification and subsequent polymerase chain reaction was normally completed. Similarly, when the MET primer pair did not amplify, amplification with the UNMET primer pair served as control. Furthermore, concurrent processing of a DNA sample from a normal individual served as a control in both cases.

Methylation status of the $5^{\prime}$ end of the SNRPN gene was evaluated by MSPCR in kidney, lung, heart, liver, adrenal, brain, and skin cells from a 17-week human fetus as well as amniocytes from 3 mid-trimester amniocenteses. DNA from all the tissues evaluated amplified with the MET and UNMET primer pairs (data not shown). DNA extracted from sperm amplified with the UNMET primer pair but not with the MET primer pair (Fig. 4a). In contrast, sperm DNA pretreated with methylase prior to bisulfite modification amplified with the MET primer pair but not with the UNMET primer pair.

Bisulfite-modified genomic DNA from a western lowland gorilla (Gorilla g.g), a "common" chimp (Pan troglodytes) and a "pygmy" chimp (Pan paniscus) amplified with both the MET primer pair and the UNMET primer pair (Fig. 4b).

Finally, sensitivity of MSPCR for detecting the methylated/ unmethylated alleles of the SNRPN gene was tested using serial dilution of genomic DNA. A range of genomic DNA concentrations (6 ng-400 ng) spiked with $1 \mu \mathrm{g}$ of salmon sperm DNA as carrier was treated with bisulfite. PCR products of expected size were successfully amplified from as little as a $1 / 10$ aliquot of the bisulfite-modified DNA obtained from 50 ng of genomic DNA (data not shown).

\section{DISCUSSION}

In the present study we have shown that MSPCR can be used to document the methylation status of the putative promoter region of the SNRPN gene. In testing patients with PWS, the assay herein presented has a specificity of $100 \%(50 / 50)$ and a sensitivity of $100 \%$ (10/10). In evaluating patients with AS, the specificity was $100 \%(50 / 50)$ and the sensitivity was $100 \%(5 / 5)$. We have not observed any false positive results for either PWS or AS in the 50 normal control samples. With respect to a false negative result, none have been observed in the 10 patients with PWS or the 5 patients with AS. In addition, studies on human sperm DNA demonstrated the high degree of specificity of MSPCR assay at the promoter region of the SNRPN gene. Human sperm DNA (paternal) amplified only with the UNMET primer pair as expected from a previous study which showed that human sperm is unmethylated [Glenn et al., 1996]. Furthermore, CpG methylasetreated sperm DNA amplified only with the MET primer pair, reflecting an in vitro change in methylation status. In that MSPCR can detect all presently testable causes of PWS and AS in a rapid and costeffective fashion, serious consideration should be given to the use of this analysis in the initial evaluation of all patients in which PWS or AS is being considered.

A false positive result for PWS or AS could occur if there was a sequence polymorphism in the base which is to be annealed to by the $3^{\prime}$ end of either forward or reverse primer of the UNMET pair in the case of PWS and or the MET pair in the case of AS. In PWS the test result could be falsely interpreted as negative if a sequence polymorphism (especially cytosine to thymine conversion) was present in the bases which are to be annealed by the $3^{\prime}$ end of both forward and reverse primers of the UNMET pair. However, such base changes at two separate locations would be extremely rare. In AS, the test result could be falsely interpreted as negative if a large amount of partially modified UNMET strands, which contain cytosines in a random fashion, coincidentally matches with the completely modified methylated allele and permits amplification with the MET primer pair. However, the observation that none of the incompletely modified AS-patient DNA subjected to successively shorter bisulfite treatment (1h, 3.5h, 7h, 10h, and 13h) amplified with MET primer pair (data not shown) indicates that such concern is of a theoretical nature only.

The validity of this assay is based on the following two assumpti ons: 1) There is little if any sequence polymorphism in the oligonudeotide priming sites. Data from this study support that assumption. Both the MET and UNMET primer pairs amplified products of expected size in 50 normal unrelated individuals. In addition, bisulfite-modified genomic DNA from a western lowland gorilla, a "common" chimp, and a "pygmy" chimp amplified with both the MET and UNMET primer pairs indicating that those target sequences of the primer sets are highly conserved evolutionarily. Thus, it is unlikely that there is significant sequence polymorphism in the region homologous to the primer pairs among humans. It is also important to note that 


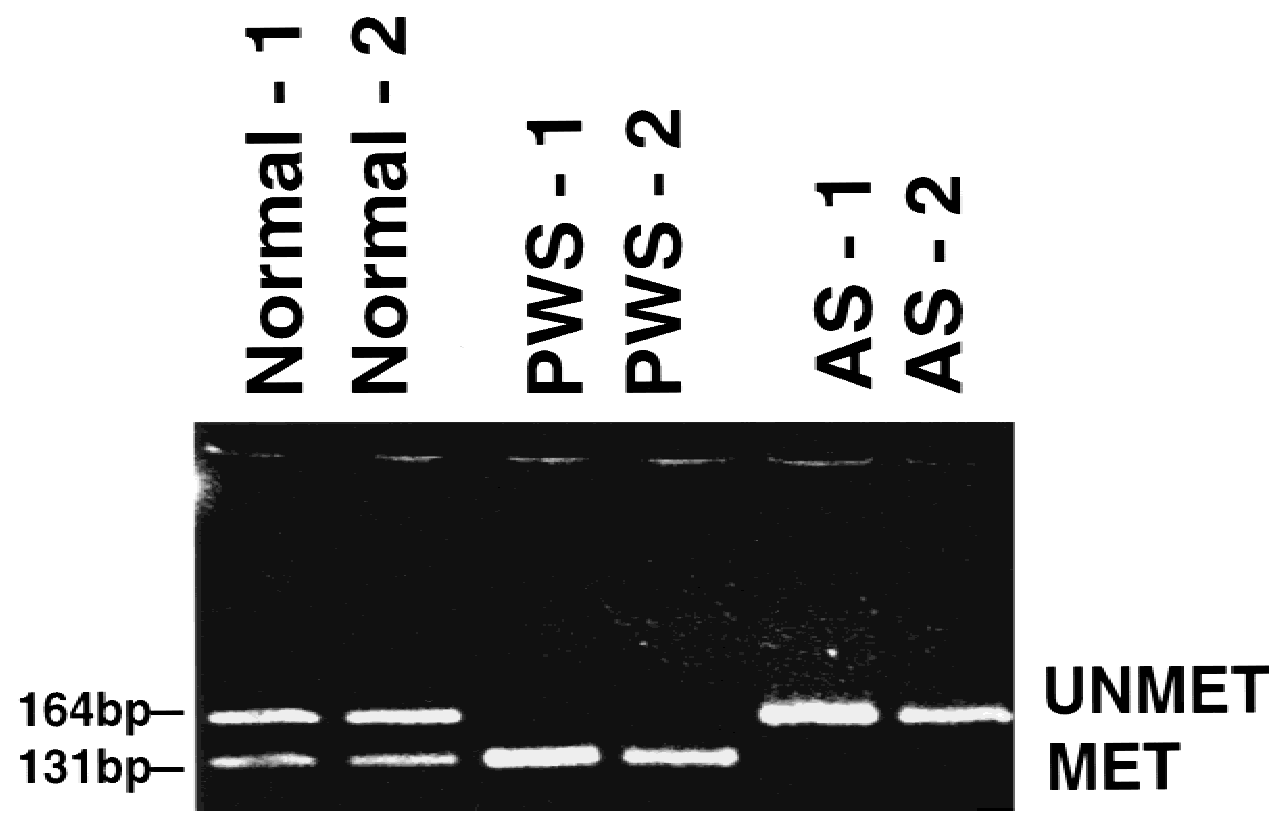

Fig. 3. Diagnosis of PWS/AS using MSPCR. PCR product from a modified DNA using the MET and the UNMET primer pairs were mixed and electrophoresed in the same lane of a 4\% agarose gel. The MET primer pair amplified the smaller product (131 bp) while the UNMET primer pair amplified the larger product (164 bp). Note that normal individuals (lanes $\mathbf{1}$ and 2) had both alleles. Patients with PWS (Ianes $\mathbf{3}$ and $\mathbf{4}$ ) had only the methylated allele while those with AS (Ianes $\mathbf{5}$ and 6) had only the unmethylated allele.

the conventional assay using methylation-sensitive restriction enzymes is also prone to sequence polymorphism in that any base substitution in the recognition sequence of the enzymes will lead to nondigestion and ther efore would lead to an anomal ous test result. 2) All CpG dinucleotides in the target sequences of the primer pairs are methylated in the maternally derived

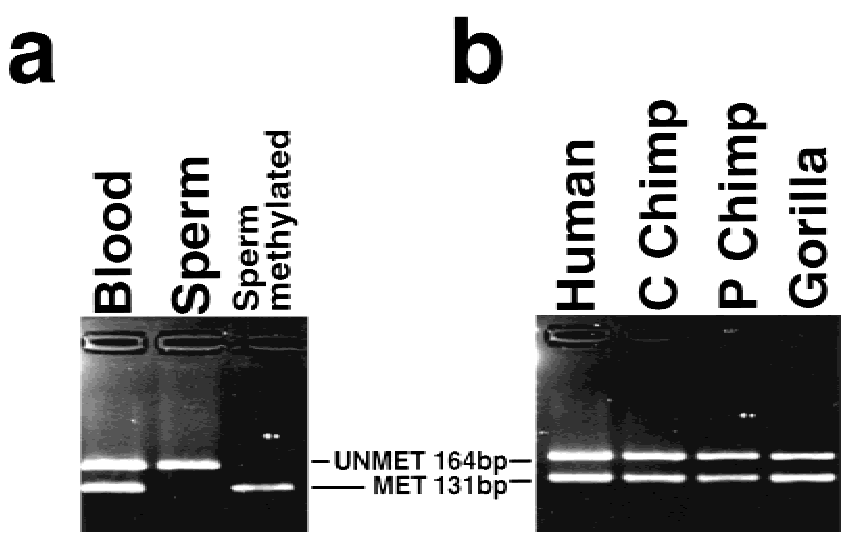

Fig. 4. Methylation analysis of the promoter region of SNRPN using MSPCR. PCR product from a modified DNA with the MET primer pair and that with the unmethylated allele-specific primer pair (UNMET) were combined and were electrophoresed on a $4 \%$ agarose gel. The MET primer pair amplified the smaller product (131 bp) while the UNMET primer pair amplified the larger product (164 bp). a: Methylation analysis of SNRPN in sperm DNA before and after methylase treatment. Whole blood from a normal individual (lane 1) had one methylated allele and one unmethylated allele while the sperm (lane 2) had only the unmethylated allele. When genomic DNA from sperm was treated with CpG methylase prior to bisulfite modification, apparently only the "methylated" allele was present (lane 3). b: Methylation analysis of SNRPN in primates. Modified DNA from a "common" chimp (lane 2), a "pygmy" chimp (lane 3) and a gorilla (lane 4) as well as human (lane 1) all amplified with both the MET primer pair and the UNMET primer pair. chromosome. This was predicted from a previous study based on a methylation study using multiple methylation-sensitive enzymes [Glenn et al., 1996] which showed that 4 out of 7 CpG dinucleotides between position -55 and +16 of the SNRPN gene are methylated. Genomic sequencing performed in this study showed that the remaining $3 \mathrm{CpG}$ dinucleotides are also methylated.

The MSPCR assay used in this study to document the methylation status of the putative promoter region of the SNRPN gene is comparable to the amplificationrefractory mutation system (ARMS) which has been successfully used for detection of point mutations and small deletions in such disorders as cystic fibrosis [Newton et al., 1989; Ferrie et al., 1992; Miedzybrodzka et al., 1994] and adenomatous polyposis coli [Cama et al., 1995]. Both assays are based on the observation that oligonucleotides complementary to a given DNA sequence except for a mismatch at the $3^{\prime}$ terminus will not amplify. MSPCR is more stringent than ARMS in discriminating alleles in that mismatches are incorporated not only at the $3^{\prime}$ termi nus but al so at other bases close to the $3^{\prime}$ end, and mismatches are incorporated at the $3^{\prime}$ end of both the forward and the reverse primers. Thus it is expected that MSPCR will be at least as reliable as ARMS.

The method herein presented has the following significant advantages over conventional analysis using methylation-sensitive enzymes and Southern blotting: (1) MSPCR can be completed in 2 days. Rapid turnaround of the test result will be especially useful when evaluating hypotonic newborn infants among whom the incidence of PWS is high [Gillessen-Kaesbach et al., 1995]; (2) Testing can be performed with as little as 50 ng of genomic DNA. Thus, in addition to whole blood, 
other potential sources of genomic DNA for analysis include dried blood spots and buccal cell smears; (3) MSPCR does not require use of radioactivity. Therefore, any laboratory with the ability to perform PCR will be able to complete this assay.

Finally, in addition to its clinical application, MSPCR could be utilized for basic research in developmental biology. In that MSPCR requires a very small amount of tissue, methylation status of the SNRPN gene could be delineated in very young embryos and cells undergoing gametogenesis. Such studies will be helpful in correlating methylation with parent-oforigin-specific expression which has recently been delineated using RT-PCR [Barr et al., 1995] and single nucleotide primer extensi on (SNuPE) assay [Szabó and Mann, 1994, 1995].

\section{ACKNOWLEDGMENTS}

This study was supported by the Research Support Fund from Children's Hospital-San Diego Research Center. ANV is a Howard Hughes Medical Institute predoctoral fellow. The authors thank Drs. Marilyn C. J ones and Lynne M. Bird at Children's Hospital-San Diego and Dr. Oliver W. J ones at University of California, San Diego for evaluating patients, and Dr. O.A. Ryder at the Zoological Society of San Diego's Center for Reproduction of Endangered Species for providing DNA of nonhuman primates.

\section{REFERENCES}

Barr J A, J ones J , Glenister PH, Cattanach BM (1995): U biquitous expression and imprinting of Snrpn in the mouse. Mammal Genome 6:405407.

Buiting K, Saitoh S, Gross S, Dittrich B, Schwartz S, Nicholls RD, Horst hemke B (1995): I nherited microdeletions in the Angel man and PraderWilli syndrome define an imprinting centre on human chromosome 15. Nat Genet 9:395-400

Cama A, Palmirotta R, Curia MC, Ranieri A, Ficari F, Valanzano R, Battista P, Modesti A, Tonelli F (1995): Multiplex PCR analysis and genotype-phenotype correlations of frequent APC mutations. Hum Mutat 5:144-152.

Clark SJ , Harrison J , Paul CL, Frommer M (1994): High sensitivity mapping of methylated cytosines. Nucleic Acids Res 22:2990-2997.

Dittrich B, Robinson WP, Knoblauch H, Buiting K, Schmidt K, GillessenKaesbach G, Horsthemke B (1992): Molecular diagnosis of the PraderWilli and Angelman syndromes by detection of parent-of-origin specific DNA methylation in 15q11-q13. Hum Genet 90:313-315.

Ferrie RM, Schwarz MJ , Robertson NH, Vaudin S, Super M, Malone G, Little S (1992): Development, multiplexing, and application of ARMS tests for common mutations in the CFTR gene. Am J Human 51:251262.

Gillessen-Kaesbach G, Gross S, Kaya-Westerloh S, Passarge E, Horsthe mke B (1995): DNA methylation based testing of 450 patients suspected of having Prader-Willi syndrome. J Med Genet 32:88-92.

Glenn CC, Nicholls RD, Robinson WP, Saitoh S, Niikawa N, Schinzel A Horsthemke B, Driscoll DJ (1993): Modification of 15q11-q13 DNA methylation imprints in unique Angelman and Prader-Willi patients. Hum Mol Genet 2:1377-1382.

Glenn CC, Saitoh S, J ong MTC, Filbrandt MM, Surti U, Driscoll DJ , Nicholls RD (1996): Gene structure, DNA methylation, and imprinted expression of the human SNRPN gene. Am J Hum Genet 58:335-346.

Guisti A, Baird M, Pasquale S, Balazs I, Glassberg J (1986): Application of Deoxyribonucleic acid (DNA) polymorphisms to the analysis of DNA recovered from sperm. J Forens Sci 31:409-417.

Herman J G, Graff J R, Myöhänen, Nelkin BD, Baylin SB (1996): Methylation-specific PCR: A novel PCR assay for methylation status of CpG islands. Proc Natl Acad Sci USA 93:9821-9826.
Knoll J HM, Nicholls RD, Magenis ER, Graham J r J M, Lalande M, Latt SA (1989): Angelman and Prader-Willi syndrome share a common chromosome 15 deletion but differ in parental origin of the deletion. Am J Med Genet 32:285-290.

Kubota T, Sutcliffe J S, Aradhya S, Gillessen-Kaesbach G, Christian SL, H orsthemke B, Beaudet AL, Ledbetter DH (1996): Validation studies of SNRPN methylation as a diagnostic test for Prader-Willi syndrome. Am J Med Genet 66:77-80.

Magenis ER, Toth-Fejal S, Allen LJ , Black M, Brown MG, Budden S, Cohen $R$ (1990): Comparison of the $15 q$ deletions in Prader-Willi syndrome and Angelman syndromes: Specific regions, extent of deletions, parental origin, and clinical consequences. Am J Med Genet 35:333349.

Malcolm S, Clayton-Smith J , Nicholls RD, Robb S, Webb T, Armour J AL, J effreys AJ , Pembrey ME (1991): Uniparental paternal disomy in Angelman syndrome. Lancet 337:694-697.

Mascari MJ, Rogan PK, Ladda RL, Butler MG, Gottlieb W, Nicholls RD (1992): Molecular diagnosis of Prader-Willi syndrome. N Engl J Med 326:1599-1607.

Miedzybrodzka ZH, Yin Z, Kelly KF, Haites NE (1994): Evaluation of laboratory methods for cystic fibrosis carrier screening: Reliability, sensitivity, specificity, and costs. J Med Genet 31: 545-550.

Newton CR, Graham A, Heptinstall LE, Powell SJ , Summers C, Kalsheker N, Smith J C, Markham AF (1989): Analysis of any point mutation in DNA. The amplification refractory mutation system (ARMS). Nucleic Acids Res 17:2503-2516.

Nicholls RD (1993): Genomic imprinting and candidate genes in PraderWilli and Angelman syndromes and mouse models. Curr Opin Genet Dev 3:445-456.

Nicholls RD, Knoll J H, Glatt K, Hersh J H, Brewster TD, Graham J r J M, Wurster-Hill D, Wharton R, Latt SA (1989a): Restriction fragment length polymorphisms within proximal $15 q$ and their use in molecular cytogenetics and the Prader-Willi syndrome. Am J Med Genet 33:6677.

Nicholls RD, Knoll J H, Butler MG, Karam S, Lalande M (1989b): Genetic imprinting suggested by maternal uniparental heterodisomy in nondeletion Prader-Willi syndrome. Nature 342:281-285.

Nicholls RD, Pai GS, Gottlieb W, Cantú ES (1992): Paternal uniparental disomy of chromosome 15 in a child with Angelman syndrome. Ann Neurol 32:512-518.

Nur I, Szyf M, Razin A, Glaser G, Rottem S, Razin S (1985): Procaryotic and eucaryotic traits of DNA methylation in Spiroplasmas (Mycoplasmas). J Bacteriol 164:19-24.

Reis A, Dittrich B, Greger V, Buiting K, Lalande M, Gillessen-Kaesbach G, Anvret M, Horsthemke B (1994): Imprinting mutations suggested by abnormal DNA methylation patterns in familial Angel man and PraderWilli syndromes. Am J Hum Genet 54:741-747.

Robinson WP, Bottani A, Xie YG, Balakrishman J, Binkert F, Mächler M, Prader A, Schinzel A (1991): Molecular, cytogenetic, and clinical investigations of Prader-Willi syndrome patients. Am J Hum Genet 49: 1219-1234.

Shapiro R, Braverman B, Louis J B, Servis RE (1973): Nucleic acid reactivity and conformation. II. Reaction of cytosine and uracil with sodium bisulfite. J Biol Chem 248:4060-4064.

Sutcliffe J S, Nakao M, Christian S, Örstavik KH, Tommerup N, Ledbetter $\mathrm{DH}$, Beaudet AL (1994): Deletion of a differentially methylated CpG island at the SNRPN gene define a putative imprinting control region. Nat Genet 8:52-58.

Szabó PE, Mann J R (1994): Biallelic expression of imprinted genes in the mouse germ line: I mplications for erasure, establishment, and mechanisms of genomic imprinting. Genes Dev 9:1857-1868.

Szabó PE, Mann J R (1995): Allele specific expression and total expression of imprinted genes during early mouse development: I mplications for imprinting mechanisms. Genes Dev 9:3097-3108.

Wang RYH, Gehrke CW, Ehrlich M (1980): Comparison of bisulfite modification of 5-methyl deoxycytidine and deoxycytidine residues. Nucl Acid Res 8:4777-4790.

Williams CA, Zori RT, Stone J W, Gray BA, Cantú ES, Ostrer H (1990): Maternal origin of 15q11-q13 deletions in Angelman syndrome suggests a role for genomic imprinting. Am J Med Genet 35:350-353.

Zackowski J L, Nicholls RD, Gray BA, Bent-Williams A, Gottlieb W, Harris PJ , Waters MF, Driscoll DJ , Zori RT, Williams CA (1993): Cytogenetic and molecular analysis in Angelman syndrome. Am J Med Genet 46: 7-11. 